\title{
Abnormal alignment of the left lower extremity and irregular gait
}

\section{Pamela Walsh $^{1} \cdot$ Lynne Pinkney $^{2} \cdot$ Mohammad Samim $^{1}$}

Published online: 13 February 2018

(C) ISS 2018

History: 2-year-old male with abnormal alignment of the left lower extremity and irregular gait (Fig. 1).

The diagnosis can be found at https://doi.org/10.1007/s00256-018-2913-9

Pamela Walsh

pamela.julia.walsh@gmail.com

1 New York University, 333 East 38th Street, 6th Floor, New York, NY 10016, USA

2 New York University, 560 First Avenue, Second Floor, New York, NY 10016, USA 

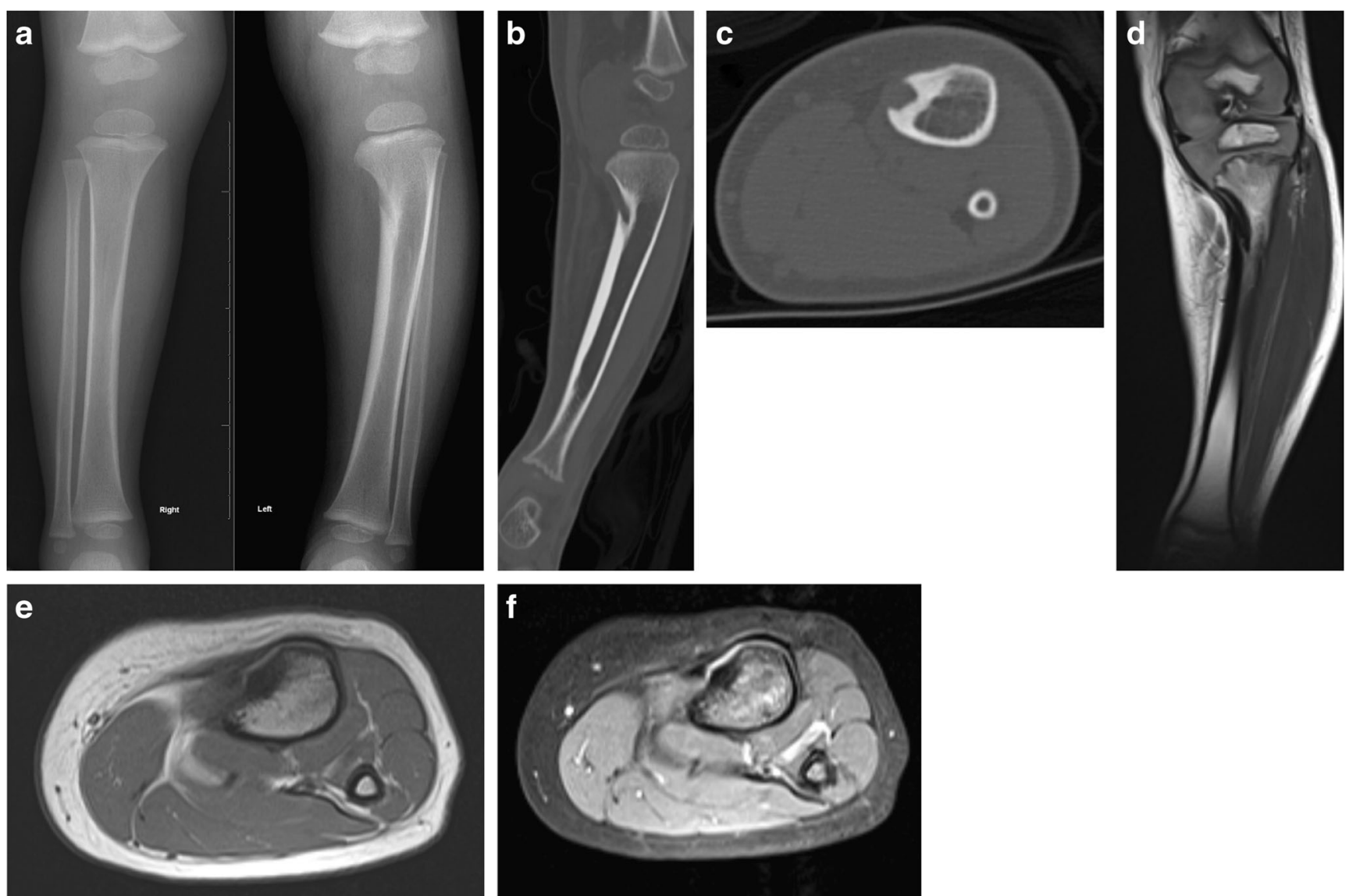

Fig. 1 a Bilateral tibia/fibula radiograph. b Coronal CT image. c Axial CT image. d T1 weighted coronal image. e T1 weighted axial image. f Post contrast $\mathrm{T} 1$ fat suppressed axial image 